\title{
A World Without Law; A World Without Politics
}

\author{
Robert Post
}

I have read with great interest the stimulating contributions of Liav Orgad, Rainer Bauböck, Primavera De Filippi, and Francesca Strumia. It is important to ask how a universal internet will affect the nature of citizenship, the status of which has heretofore been dominated by territorially-defined nation states.

I confess, however, that I know nothing about blockchain technology. So I accept Orgad's assertion that blockchain technology 'can provide people with self-sovereign identity - they are the ones who create and register their identity and they are the only ones who control what to do with it and with whom to share what.' I accept that nation states can off-load this identification function to some technological mechanism.

But Orgad seems to believe that this mechanism creates the possibility of 'realizing one of the most morally-desirable notions in human history global citizenship without a world state.' This is because the mechanism potentially shatters a Westphalian system in which legal personality is conferred by nation states.

Orgad writes that "the concept of an international legal persona will enable individuals to establish "Cloud Communities" of different kinds. Conceptually, cloud communities have traditional characteristics of political communities, but not necessarily a physical territory. The communal bond can be global in nature - such as a shared concern about climate change, ageing, veganism and animal rights (i.e., a universal community, open to everyone) - or ascriptive, such as a Jewish / Bahá'í faith / Diasporic Cloud Nations, a form of "transnational nationalism" (i.e., a selective community, open only to certain members). It can be thematic or geographic - region, country, state, city, village - based on a shared interest or territorial identity, even if not or legally recognised communities. Membership is based on consent; a person can be a member of several communities or none.'

So described, cloud communities are, as Rainer Bauböck properly observes, 'an expansion of civil society.' It is a far jump from expanding 
international civil society to creating global citizenship. A global citizen must be a member of a global political community. Orgad acknowledges this point. He states that his 'focus is political communities. Cloud communities are not social networks, but political communities whose aim is political decision-making and in which individuals take part in a process of governance and the creation of law.'

It is at precisely this point that I lose track of the argument. Orgad is correct to observe that the defining characteristic of political communities is the production of 'governance and the creation of law.' What I do not understand is how cloud communities produce governance and law.

By imposing sanctions of expulsion, any given cloud community can govern itself; it can create its own law. But this is true for every group within civil society. Every church has its rules and its criteria for excommunication. The point about a political community, however, is that it imposes law upon those who, as Bauböck observes, are not voluntarily members. Political communities govern all those within their jurisdiction. That is precisely the difference between political communities and a private organization. It is why law ultimately must have recourse to force, even to violence (as Max Weber observes).

A world in which every community is voluntary is a world in which every norm is also voluntary. It is therefore a world without law. Because politics is the social form by which we create law, it is also a world without politics.

If I commit murder, the necessity of my punishment is not bounded by my consent. Cloud communities, which are defined by consent, are thus irrelevant. The question is who we will entrust with the fearsome power of involuntary punishment, which is not a purely textual, purely mediated consequence. To the extent that punishment operates on the body of the guilty, it cannot be within the purview of cloud communities.

De Filippi shrewdly observes that the attraction of blockchain technologies is to create 'trustless systems (i.e. system where trust is no longer needed).' The hope that technology will remove the human element is an old one. We all long to leave behind the flesh and live only in the spirit. But this is merely a fantasy. There is always corruption, and for that reason we can never escape the need for politics, police, and law.

Suppose someone infiltrates the blockchain and manipulates it for nefarious ends. To whom will we entrust the power of ensuring the integrity of the chain? And don't think that it can never happen. It always happens. All tech- 
nology is ultimately wielded by human hands that can become dirty. Who will have the power (to use an old-fashioned word) to cleanse the chain and restore the system? And how will that power be legitimised? How will we come to trust that power?

Politics is what we use in the face of such problems, when we must confront each other as distinct human beings and reach accommodation about essential matters in which we differ. Another way of seeing this point is this: If cloud communities create, as Strumia writes, 'citizens' who can 'virtually vote with their feet,' who will protect global citizens as they travel between cloud communities?

At their best, cloud communities can inspire all the virtues that de Tocqueville saw in civil associations. They can train us in the benefits of participation and sociality. But in the contributions of Strumia and Orgad, I sense also another value, that of free, autonomous, marketplace consumers. Orgad writes that e-Estonia 'resembles a business model where states are service providers and "citizens" are billed for the service.' Strumia imagines e-states that provide services to expats or 'virtual denizens.'

Strumia and Orgad emphasise real and important developments. But it is a mistake to confuse these possibilities with the creation of political communities. Strumia and Orgad are instead describing ordinary marketplace consumer transactions. If states can sell services more cheaperly than a private entity, and if they can sell these services internationally, that may be all to the good.

But what does this have to do with law and governance? To answer this query, we need to ask questions like: Who can (involuntarily) tax virtual denizens? Who can determine the commercial law that will govern the market transactions that a state conducts with virtual denizens? and so forth. Every market transaction presupposes a legal environment that is outside the transaction itself. Setting the requirements of that environment is a political task.

It is quite true that traditional states can offload services that now we associate with governmentality. Perhaps states can offload the determination of identity status to a blockchain. As the EU has taught us, it is a mistake to confuse government sovereignty with the particular shape in which it is presently exercised. But insofar as we wish to deploy government sovereignty - insofar as we wish to exercise state functions backed by the force of law - it is a fearsome and unstable thing to do so without a corresponding political community, as the EU has also taught us. 
If the very definition of cloud communities is that they are voluntary and exist only at the whim and interest of members, I do not see how blockchain cloud communities promise the creation of global citizenship. They seem instead to signal the emergence of global civil society or at most a global market in government services. And, to the extent that cloud communities are involuntary, I must ask how their members are conscripted and governed. I must also ask how blockchains or any other technological device can offer hope that governance will be more just or more democratic than what presently exists in traditional territorially-bounded nation states.

Open Access This chapter is licensed under the terms of the Creative Commons Attribution 4.0 International License (http://creativecommons.org/licenses/by/4.0/), which permits use, sharing, adaptation, distribution and reproduction in any medium or format, as long as you give appropriate credit to the original author(s) and the source, provide a link to the Creative Commons license and indicate if changes were made.

The images or other third party material in this chapter are included in the chapter's Creative Commons license, unless indicated otherwise in a credit line to the material. If material is not included in the chapter's Creative Commons license and your intended use is not permitted by statutory regulation or exceeds the permitted use, you will need to obtain permission directly from the copyright holder.

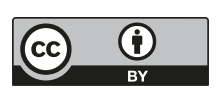

